\title{
Serum PTH is not a good marker for defining a threshold for vitamin D deficiency
}

\author{
Rolf Jorde ${ }^{1,2}$ and Guri Grimnes ${ }^{1,2}$ \\ ${ }^{1}$ Troms $\varnothing$ Endocrine Research Group, Department of Clinical Medicine, UiT The Arctic University of Norway, Tromsø, Norway \\ ${ }^{2}$ Division of Internal Medicine, University Hospital of North Norway, Tromsø, Norway
}

Correspondence should be addressed to R Jorde: rolf.jorde@unn.no

\begin{abstract}
Objective: In addition to its skeletal effects, vitamin $\mathrm{D}$ may also be important for health in general. It is uncertain what level of serum 25-hydroxyvitamin D (25(OH)D), marker of vitamin D status, is sufficient for these effects. With decreasing serum 25(OH)D levels there is an increase in serum PTH. The point at which this occurs has been considered as a threshold for vitamin D sufficiency. The thresholds found have varied widely and have mainly been based on observational studies. However, to truly establish a threshold for vitamin D effects, this has to be based on randomized controlled trials (RCTs).

Methods: The study included 2803 subjects from a general health survey, the Troms $\varnothing$ study, and pooled individual person data from five vitamin $D$ intervention studies $(n=1544)$. Serum parathyroid hormone (PTH) and change in PTH after vitamin D supplementation were related to serum $25(\mathrm{OH}) \mathrm{D}$ levels in steps of $25 \mathrm{nmol} / \mathrm{L}(<24$, 25-49, 50-74, 75-99, and $>99 \mathrm{nmol} / \mathrm{L}$ ).

Results: In the Tromsø study, in the females there was a gradual decrease in serum PTH with increasing serum $25(\mathrm{OH}) \mathrm{D}$ with no apparent plateau, whereas in the males the decrease in PTH in subjects with serum $25(\mathrm{OH}) \mathrm{D}>74 \mathrm{nmol} / \mathrm{l}$ was marginal. In pooled RCTs, there was a significant reduction in serum PTH by vitamin $D$ supplementation regardless of baseline serum 25(OH)D level. Conclusions: The use of the serum PTH-25(OH)D relation from observational studies to determine a threshold for vitamin $\mathrm{D}$ sufficiency is highly questionable.
\end{abstract}

\author{
Key Words \\ - parathyroid hormone \\ - thresholds \\ - vitamin D \\ - randomized controlled trial
}

\section{Introduction}

Vitamin D is essential for intestinal calcium absorption and skeletal health. Vitamin D deficiency in children may lead to rickets, which can be prevented and/or treated by vitamin D supplementation (1). In addition to its importance in calcium metabolism and bone health, vitamin D may potentially also have a number of other health effects. Thus, low serum levels of 25-hydroxyvitamin D (25(OH)D), which is the currently accepted marker of vitamin D status, are associated with development of cancer, cardiovascular diseases (CVD), diabetes, infections, and immunological diseases (2). However, most intervention studies have so far not been able to prove positive effects of vitamin D supplementation $(3,4)$, except perhaps in those with very low baseline serum 25(OH)D levels (5).

During the last decade, there has been considerable debate as to which serum $25(\mathrm{OH}) \mathrm{D}$ level is sufficient or optimal. The institute of medicine (IOM) has recommended that a level of $50 \mathrm{nmol} / \mathrm{L}$ is sufficient (6), whereas a level of $75 \mathrm{nmol} / \mathrm{L}$ has been recommended by the Endocrine Society (7). These recommendations are partly based on calcium absorption, presence of signs of osteomalacia, as well suppression of serum parathyroid hormone (PTH) by vitamin D $(6,7,8)$. 
Since the serum PTH secretion is mainly regulated by the serum calcium level, where a low calcium level simulates PTH secretion and a high level inhibits, vitamin D may suppress serum PTH levels indirectly by its effect on intestinal calcium absorption. Vitamin D may also have a direct effect on PTH synthesis and secretion since the active form of vitamin D, 1,25-dihydroxyvitamin D $\left(1,25(\mathrm{OH}) \mathrm{D}_{2}\right)$, represses the transcription of PTH as well as the expression of the calcium-sensing receptor (9). Accordingly, a reverse relation between serum PTH and $25(\mathrm{OH}) \mathrm{D}$ has been repeatedly demonstrated, and most studies find a sharp increase in serum PTH in the lowest serum $25(\mathrm{OH}) \mathrm{D}$ ranges $(10,11,12)$. The serum $25(\mathrm{OH}) \mathrm{D}$ level where this PTH increase starts has by many been taken as a threshold level for sufficient serum 25(OH)D.

This threshold level has been reported as low as $30 \mathrm{nmol} / \mathrm{L}$ and as high as $100 \mathrm{nmol} / \mathrm{L}$ (4), and there are even studies where such a threshold or plateau has not been found at all (13). Most of these studies have been cross-sectional, and to truly define a threshold where a higher serum 25(OH)D level will not lead to further PTH suppression, this has to be based on randomized controlled trials (RCTs) (4). Numerous vitamin D RCTs have included serum 25(OH)D and PTH measurements (14), but to our knowledge, none has specifically evaluated the effect of vitamin D supplementation on serum PTH in subjects with high baseline serum 25(OH)D levels.

At the Clinical Research Unit, University Hospital of North Norway, we have performed a number of vitamin D RCTs and thus have a huge database on PTH responses to vitamin D supplementation. Furthermore, the seventh survey of the Tromsø study was recently performed, where $>3000$ subjects had both serum 25(OH)D and PTH measured. We, therefore, had the opportunity to evaluate the PTH-25(OH)D relation both from a cross-sectional and interventional point of view.

\section{Materials and methods}

\section{Subjects}

Individual participant data from the seventh survey of the Tromsø study and six intervention studies performed in Tromsø, Northern Norway, are used in the present analyses. These studies have been described in detail before and are summarized in short subsequently.

The Tromsø study is a population-based health survey performed for the first time in 1974 in Tromsø,
Northern Norway at $69^{\circ}$ North. The seventh survey was performed in 2015-2016. All citizens aged 40 years and above and living in the municipality of Tromsø were invited and 21,083 (64.7\%) attended $(15,16)$. Serum PTH was measured in a subgroup of 3769 subjects who also had attended the fourth survey in 1994-1995.

The Obesity study (performed 2005-2007) included 445 overweight subjects, randomized to vitamin D 4 0,000 IU per week, 20,000 IU per week, or placebo for 1 year. All subjects were also given $500 \mathrm{mg}$ calcium daily. The primary end point was weight reduction after 1 year. The subjects met to visits every third month (17).

The Depression study (performed 2008-2010) included 243 healthy subjects randomized to vitamin D $40,000 \mathrm{IU}$ per week vs placebo for 6 months. The main endpoint was reduction in symptoms of depression evaluated with a range of depression inventories and scales (18). The study was registered at ClinicalTrials.gov (NCT00960232).

The Glucose clamp study (performed 2008-2010) included 108 healthy subjects randomized to vitamin D 40,000 IU per week vs placebo for 6 months. The main endpoint was change in insulin sensitivity and secretion, as evaluated by a hyperglycemic glucose clamp technique (19). The study was registered at ClinicalTrial.gov (NCT00809744).

The Osteoporosis study (performed 2007-2010) included 297 postmenopausal women with bone mass density (BMD) T-score $\leq-2.0$ in either lumbar spine or total hip. They were randomized to $6500 \mathrm{IU}$ vitamin D per day (20,000 IU twice per week +800 IU per day) or 800 IU vitamin D per day (placebo +800 IU per day) for 1 year and met to visits every third month. Both groups were given $1000 \mathrm{mg}$ elemental calcium per day. The primary endpoint was change in BMD (20).

The CVD risk factor study (performed 2015-2017) included 422 healthy subjects randomized to vitamin D (100,000 IU loading dose, followed by 20,000 IU per week) or placebo for 4 months. The main endpoints were change in CVD risk factors (21). The study was registered at ClinicalTrials.gov (NCT02750293).

The Prevention of T2DM study (performed 20082015) included 511 subjects with prediabetes who were randomized to vitamin D 20,000 IU per week vs placebo for 5 years. The subjects met to visits annually. The main endpoint was progression to type 2 diabetes (T2DM) (22). The study was registered at ClinicalTrials.gov (NCT00685594).
This work is licensed under a Creative Commons Attribution-NonCommercial 4.0 International License. ded from Bioscientifica.com at 04/26/2023 06:22:13AM via free access 


\section{Measurements}

Serum 25(OH)D was determined in the Depression, Glucose clamp, and Osteoporosis studies at the Hormone Laboratory, Haukeland University Hospital, Bergen, using an in-house-developed liquid chromatography double mass spectrometry (LC/MS-MS) method. All other biochemical analyses were performed at the Department of Medical Biochemistry, University Hospital of North Norway, Tromsø. Both laboratories take part in the external quality program DEQAS. Serum 25(OH)D in the Obesity study was determined by immunometry (electrochemiluminescence: ECLIA) using an automated clinical chemistry analyser (Modular E170, Roche Diagnostics) and in the three other studies by an in-house-developed LC/MS-MS method. Serum PTH in the Tromsø study and the CVD risk factor study was analysed with an electrochemiluminescence immunoassay (ECLIA) using an automated clinical chemistry analyser (Cobas 6000, Roche) and serum calcium by an automated analyser (Modular P, Roche Diagnostics) with reagents from Boehringer Mannheim. In the five other studies, serum PTH was measured using an automated clinical chemistry analyzer (Immulite 2000, Siemens Healthcare Diagnostics) and serum calcium with an automated analyser (Hitachi 917) with reagents from Boehringer Mannheim. Reference ranges for serum PTH were 1.1-6.8 pmol/L for those $<51$ years and $1.1-7.5 \mathrm{pmol} / \mathrm{L}$ for those $>50$ years and for serum calcium $2.20-2.50 \mathrm{mmol} / \mathrm{L}$.

Height and weight were measured wearing light clothing, and BMI was calculated as $\mathrm{kg} / \mathrm{m}^{2}$.

\section{Statistical analyses}

Normal distribution was evaluated for skewness and curtosis and by visual inspection of histograms and found normal except for serum PTH which was normalized by log transformation before use as dependent variable. Comparisons between groups were performed with Student's t-test or with a general linear model with adjustments as indicated in the text. Linear trends were evaluated with linear regression with adjustments as indicated in the tables. Only subjects who completed the studies and had valid serum 25(OH)D and PTH measurements were included. In the Prevention of T2DM, two cohorts were analysed, all those who completed 1 year and those who completed 5 years.

The data are shown as mean \pm s.D. All tests were done two-sided, and a $P$-value $<0.05$ was considered statically significant. The $P$-values are shown without corrections for multiple comparisons.

\section{Ethics}

All studies were approved by the Regional Committee for Medical and Health Research Ethics (REK Nord) and only participants with valid written consent were included.

\section{Results}

\section{The seventh survey of the Tromsø study}

Three thousand seven hundred sixty-nine subjects had valid serum $25(\mathrm{OH}) \mathrm{D}$ and PTH measurements. Among these, 2803 (1682 females and 1121 males) had serum calcium in the range $2.20-2.50 \mathrm{mmol} / \mathrm{L}$ and serum creatinine $<100 \mu \mathrm{mol} / \mathrm{L}$ and were included in the analyses. When all subjects were analysed together, as well as in females and males separately, there was with increasing serum 25(OH)D level (in steps of $25 \mathrm{nmol} / \mathrm{L}$ ) a significant increase in age and serum calcium and a significant decrease in serum PTH and BMI (Table 1). The decrease in serum PTH was attenuated with higher serum 25(OH)D levels. However, when comparing those in the serum $25(\mathrm{OH}) \mathrm{D}$ group of $74-99 \mathrm{nmol} / \mathrm{L}$ with those in the group with serum $25(\mathrm{OH}) \mathrm{D}>99 \mathrm{nmol} / \mathrm{L}$ and adjusting for age and BMI, the serum PTH levels were significantly $(P<0.01)$ lower in the latter group. This was also seen when analysing the females separately, whereas the difference in serum PTH between these two serum $25(\mathrm{OH}) \mathrm{D}$ groups was not statistically significant for males. However, in males, when comparing the serum 25(OH)D 50-74 nmol/L group with the serum 25(OH)D 75-99 nmol/L group, the difference in serum PTH was statistically significant $(P<0.05)$ (Table 1$)$. This apparent difference between females and males, as well as the increasingly higher PTH levels in the lower serum 25(OH)D ranges, are further illustrated in Figs 1 and 2, where the serum 25(OH)D levels between 20 and $100 \mathrm{nmol} / \mathrm{L}$ are divided in steps of $10 \mathrm{nmol} / \mathrm{L}$. In the females, there appeared to be a gradual decrease in serum PTH also with serum $25(\mathrm{OH}) \mathrm{D}>50 \mathrm{nmol} / \mathrm{L}$, whereas the corresponding decrease in the males was marginal.

\section{Pooled intervention studies}

The baseline characteristics of the subjects who completed the intervention and had valid serum 25(OH)D and PTH measurements are shown for each of the intervention studies in Table 2 . When the Obesity $(n=332)$, Depression ( $n=228)$, Glucose clamp $(n=93)$, CVD risk factors $(n=411)$, and Prevention of T2DM ( $n=480$ (subjects who

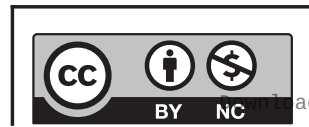

This work is licensed under a Creative Commons Attribution-NonCommercial 4.0 International License. ded from Bioscientifica.com at 04/26/2023 06:22:13AM 
Table 1 Age, BMI, serum PTH, and calcium in relation to serum 25(OH)D levels in 2803 subjects in the seventh survey of the Tromsø study.

\begin{tabular}{|c|c|c|c|c|c|}
\hline & \multicolumn{5}{|c|}{ Serum 25(OH)D $(\mathrm{nmol} / \mathrm{L})$} \\
\hline & $<25$ & $25-49$ & $50-74$ & $75-99$ & $>99$ \\
\hline All subjects $(n)$ & 23 & 459 & 1296 & 788 & 237 \\
\hline Age (years) & $66.0 \pm 13.4$ & $67.5 \pm 11.0$ & $69.6 \pm 9.9$ & $70.5 \pm 8.9$ & $71.4 \pm 8.4^{a}$ \\
\hline $\mathrm{BMI}\left(\mathrm{kg} / \mathrm{m}^{2}\right)$ & $29.4 \pm 6.3$ & $28.7 \pm 5.1$ & $27.5 \pm 4.5$ & $26.6 \pm 4.2$ & $25.7 \pm 3.9^{a}$ \\
\hline Serum 25(OH)D (nmol/L) & $22 \pm 3$ & $41 \pm 6$ & $63 \pm 7$ & $85 \pm 7$ & $113 \pm 13$ \\
\hline Serum PTH (pmol/L) & $6.8 \pm 2.7$ & $6.3 \pm 2.0$ & $5.5 \pm 1.7$ & $5.3 \pm 1.6$ & $4.9 \pm 1.5^{\mathrm{a}}$ \\
\hline Serum calcium (mmol/L) & $2.37 \pm 0.08$ & $2.35 \pm 0.07$ & $2.36 \pm 0.07$ & $2.37 \pm 0.07$ & $2.38 \pm 0.07^{a}$ \\
\hline Females $(n)$ & 12 & 226 & 760 & 517 & 167 \\
\hline Age (years) & $66.3 \pm 14.5$ & $67.5 \pm 11.5$ & $69.4 \pm 10.3$ & $70.5 \pm 8.7$ & $71.9 \pm 8.3^{a}$ \\
\hline $\mathrm{BMI}\left(\mathrm{kg} / \mathrm{m}^{2}\right)$ & $31.7 \pm 7.2$ & $28.9 \pm 5.8$ & $27.4 \pm 4.8$ & $26.4 \pm 4.5$ & $25.6 \pm 4.2^{\mathrm{a}}$ \\
\hline Serum $25(\mathrm{OH}) \mathrm{D}(\mathrm{nmol} / \mathrm{L})$ & $21 \pm 2$ & $41 \pm 7$ & $64 \pm 7$ & $85 \pm 7$ & $113 \pm 14$ \\
\hline Serum PTH (pmol/L) & $7.4 \pm 3.0$ & $6.5 \pm 2.2$ & $5.7 \pm 1.8$ & $5.3 \pm 1.6$ & $4.9 \pm 1.5^{\mathrm{a}}$ \\
\hline Serum calcium (mmol/L) & $2.38 \pm 0.07$ & $2.35 \pm 0.07$ & $2.36 \pm 0.07$ & $2.37 \pm 0.07$ & $2.39 \pm 0.06^{a}$ \\
\hline Males $(n)$ & 11 & 233 & 536 & 271 & 70 \\
\hline Age (years) & $65.6 \pm 12.6$ & $67.5 \pm 10.6$ & $69.8 \pm 9.5$ & $70.5 \pm 9.2$ & $70.2 \pm 8.5^{a}$ \\
\hline BMI $\left(\mathrm{kg} / \mathrm{m}^{2}\right)$ & $26.9 \pm 4.0$ & $28.6 \pm 4.3$ & $27.7 \pm 4.0$ & $26.8 \pm 3.6$ & $26.1 \pm 3.2^{\mathrm{a}}$ \\
\hline Serum 25(OH)D (nmol/L) & $22 \pm 4$ & $41 \pm 6$ & $63 \pm 7$ & $85 \pm 7$ & $113 \pm 10$ \\
\hline Serum PTH (pmol/L) & $6.2 \pm 2.4$ & $6.1 \pm 1.9$ & $5.3 \pm 1.6$ & $5.1 \pm 1.7$ & $5.1 \pm 1.5^{\mathrm{a}}$ \\
\hline Serum calcium (mmol/L) & $2.37 \pm 0.08$ & $2.35 \pm 0.07$ & $2.36 \pm 0.07$ & $2.36 \pm 0.07$ & $2.37 \pm 0.07^{a}$ \\
\hline
\end{tabular}

completed 1 year of the intervention)) studies were pooled together and the subjects grouped according to baseline serum 25(OH)D level $(<25,25-49,50-74,75-99$, and $>99 \mathrm{nmol} / \mathrm{L}$ ), there was with increasing baseline serum 25(OH)D, a significant decrease in baseline serum PTH, and an increase in serum calcium (Table 3).

In those given vitamin $\mathrm{D}$, the increase in mean serum $25(\mathrm{OH}) \mathrm{D}$ ranged from $70 \mathrm{nmol} / \mathrm{L}$ in those with baseline values $<25 \mathrm{nmoL} / \mathrm{L}$, to $32 \mathrm{nmol} / \mathrm{L}$ in those with baseline values $>99 \mathrm{nmol} / \mathrm{L}$. In the placebo group, there was an increase in serum $25(\mathrm{OH}) \mathrm{D}$ in those with baseline values $<50 \mathrm{nmol} / \mathrm{L}$ and a decrease in those with higher baseline values (Table 3). As compared to those given placebo,

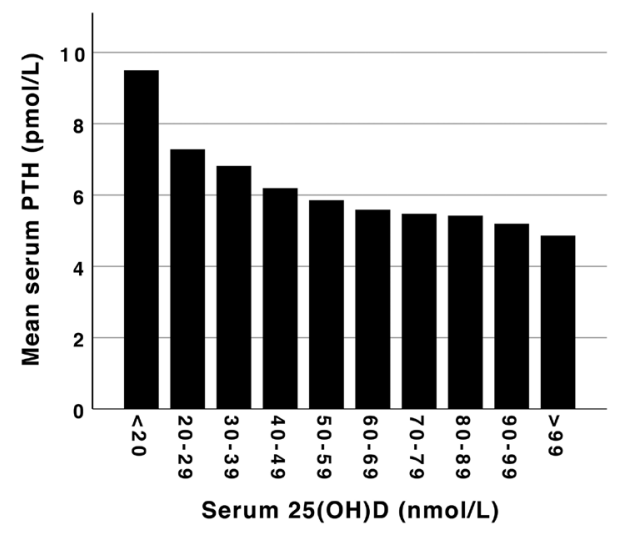

Figure 1

Mean serum PTH in relation to serum 25(OH)D in 1695 females in the seventh survey of the Tromsø study. there was an increase in serum calcium in those given vitamin $\mathrm{D}$, which was statistically significant for those with baseline serum 25(OH)D 25-49 nmol/L (Table 3). In all the baseline serum $25(\mathrm{OH}) \mathrm{D}$ groups $(<25,25-49$, 50-74, 75-99, and $>99 \mathrm{nmol} / \mathrm{L})$, those given vitamin D had a significant reduction in serum PTH compared to those given placebo. This reduction was most pronounced in those with baseline serum $25(\mathrm{OH}) \mathrm{D}<25 \mathrm{nmol} / \mathrm{L}$ (Table 3). To examine if this reduction in serum PTH by vitamin D supplementation was a result of the increase in serum calcium, the previously mentioned analyses were also done with adjustment for change in serum calcium. This made the difference in delta PTH for those in the serum

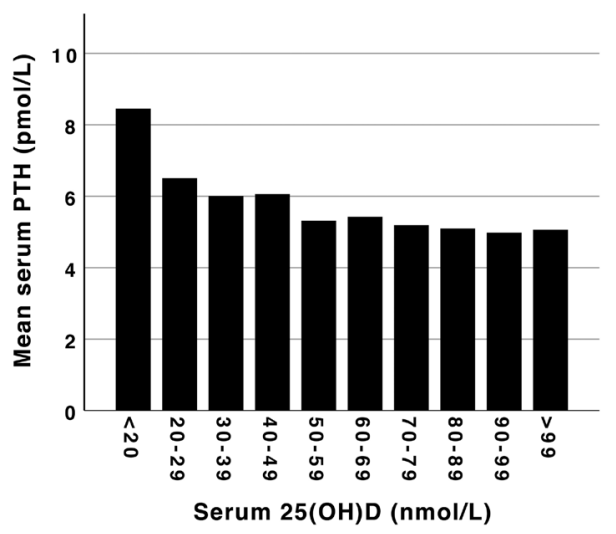

Figure 2

Mean serum PTH in relation to serum 25(OH)D in 1124 males in the seventh survey of the Tromsø study.

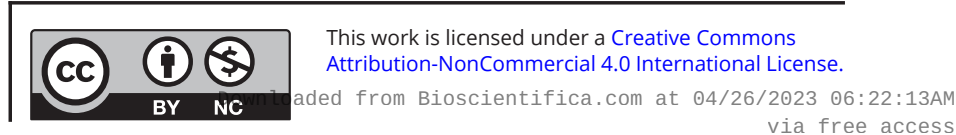


Table 2 Baseline characteristics of the six intervention studies in those who completed the study and had valid serum 25(OH)D and PTH measurements.

\begin{tabular}{|c|c|c|c|c|c|c|}
\hline Study & Females/males $(n / n)$ & Age (years) & BMI $\left(\mathrm{kg} / \mathrm{m}^{2}\right)$ & $\begin{array}{c}\text { Serum 25 }(\mathrm{OH}) \mathbf{D} \\
(\mathrm{nmol} / \mathrm{L})\end{array}$ & $\begin{array}{c}\text { Serum PTH } \\
(\mathrm{pmol} / \mathrm{L})\end{array}$ & $\begin{array}{l}\text { Serum calcium } \\
(\mathrm{mmol} / \mathrm{L})\end{array}$ \\
\hline Obesity & $203 / 129$ & $49.2 \pm 11.2$ & $34.6 \pm 3.9$ & $54 \pm 27$ & $5.4 \pm 1.7$ & $2.31 \pm 0.10$ \\
\hline Depression & $128 / 100$ & $51.8 \pm 10.2$ & $27.7 \pm 4.1$ & $48 \pm 16$ & $5.0 \pm 1.9$ & $2.28 \pm 0.08$ \\
\hline Glucose clamp & $45 / 48$ & $52.2 \pm 9.2$ & $26.8 \pm 3.0$ & $41 \pm 13$ & $5.2 \pm 1.5$ & $2.31 \pm 0.09$ \\
\hline Osteoporosis & $273 / 0$ & $63.1 \pm 7.1$ & $24.7 \pm 3.4$ & $71 \pm 23$ & $5.1 \pm 1.7$ & $2.36 \pm 0.08$ \\
\hline CVD risk factors & $192 / 219$ & $52.0 \pm 8.7$ & $27.9 \pm 4.9$ & $34 \pm 12$ & $6.7 \pm 2.0$ & $2.27 \pm 0.07$ \\
\hline Prevention of T2DM ${ }^{a}$ & $183 / 297$ & $62.0 \pm 8.6$ & $29.9 \pm 4.3$ & $61 \pm 22$ & $5.7 \pm 2.2$ & $2.31 \pm 0.08$ \\
\hline Prevention of T2DM ${ }^{b}$ & $82 / 145$ & $62.2 \pm 8.1$ & $29.3 \pm 3.8$ & $63 \pm 22$ & $5.6 \pm 2.3$ & $2.31 \pm 0.08$ \\
\hline All studies & $1024 / 793$ & $55.8 \pm 10.8$ & $29.1 \pm 5.2$ & $52 \pm 22$ & $5.7 \pm 2.0$ & $2.31 \pm 0.09$ \\
\hline
\end{tabular}

aSubjects who completed 1 year of the intervention; 'bubjects who completed 5 years of the intervention.

25(OH)D group 75-99 nmol/L non-significant $(P=0.058)$, whereas the other significance levels did not change.

\section{Effects of time and vitamin D dose on the PTH suppression}

In the Prevention of T2DM study, 227 subjects completed the 5-year intervention with valid serum 25(OH)D and PTH measurements. In the vitamin D group, there was an increase in mean serum $25(\mathrm{OH}) \mathrm{D}$ of $50-60 \mathrm{nmol} / \mathrm{L}$, whereas the serum $25(\mathrm{OH}) \mathrm{D}$ levels in the placebo group remained stable at baseline levels. There was a decrease in serum PTH in the vitamin D group compared to the placebo group, which was statistically significant after 1 , 3,4 , and 5 years. After the decrease in serum PTH during the first year, the serum PTH levels in the vitamin D group remained stable till the end of the study (Table 4).
In the Obesity study, 332 subjects completed the 1-year intervention with valid serum $25(\mathrm{OH}) \mathrm{D}$ and $\mathrm{PTH}$ measurements. In the group given vitamin D 40,000 IU per week, mean serum $25(\mathrm{OH}) \mathrm{D}$ increased $\sim 60 \mathrm{nmol} / \mathrm{L}$ and in the group given 20,000 IU per week the increase in serum $25(\mathrm{OH}) \mathrm{D}$ was $\sim 40 \mathrm{nmol} / \mathrm{L}$ and remained stable at baseline levels in the placebo group. In both vitamin D groups, the maximal decrease in serum PTH occurred already after 3 months. The decrease in serum PTH was, throughout the intervention, significantly larger in the 40,000 IU per week group as compared to the placebo group, but not as compared to the group given 20,000 IU per week (Table 5).

In the Osteoporosis study, 273 women completed the 1-year intervention with valid measurements. In the group given vitamin D 45,600 IU per week, serum $25(\mathrm{OH}) \mathrm{D}$ increased $100-115 \mathrm{nmol} / \mathrm{L}$, whereas the increase

Table 3 Baseline and change (delta values) in serum 25(OH)D, PTH, and calcium in relation to intervention and baseline serum 25(OH)D level, the Obesity, Depression, Glucose clamp, CVD risk factors, and Prevention of T2DM studies pooled together.

\begin{tabular}{|c|c|c|c|c|c|c|}
\hline & \multirow[b]{2}{*}{ Group } & \multicolumn{5}{|c|}{ Baseline serum 25 $(\mathrm{OH})$ D $(\mathrm{nmol} / \mathrm{L})$} \\
\hline & & $<25$ & $25-49$ & $50-74$ & $75-99$ & $>99$ \\
\hline \multirow[t]{2}{*}{ Number of subjects ${ }^{f}$ (females/males) } & Vitamin D & $24 / 43$ & $196 / 214$ & $136 / 133$ & $45 / 33$ & $5 / 7$ \\
\hline & Placebo & $28 / 34$ & $162 / 168$ & $115 / 130$ & $33 / 24$ & $7 / 7$ \\
\hline \multirow[t]{2}{*}{ Baseline serum 25(OH)D (nmol/L) } & Vitamin D & $20 \pm 4$ & $38 \pm 7$ & $60 \pm 7$ & $83 \pm 7$ & $122 \pm 24$ \\
\hline & Placebo & $20 \pm 4$ & $38 \pm 7$ & $60 \pm 7$ & $84 \pm 7$ & $113 \pm 15$ \\
\hline \multirow[t]{2}{*}{ Delta serum 25(OH)D (nmol/L) } & Vitamin D & $67 \pm 26^{c}$ & $67 \pm 33^{c}$ & $53 \pm 29^{c}$ & $48 \pm 29^{c}$ & $32 \pm 32^{\text {ce }}$ \\
\hline & Placebo & $7 \pm 9$ & $3 \pm 13$ & $-1 \pm 17$ & $-7 \pm 17$ & $-16 \pm 17^{e}$ \\
\hline \multirow[t]{2}{*}{ Baseline serum PTH (pmol/L) } & Vitamin D & $7.1 \pm 2.5$ & $5.9 \pm 2.1$ & $5.5 \pm 1.9$ & $4.8 \pm 1.6$ & $5.5 \pm 2.1^{\mathrm{e}}$ \\
\hline & Placebo & $7.2 \pm 2.3$ & $6.2 \pm 2.2$ & $5.3 \pm 1.8$ & $4.9 \pm 1.7$ & $4.2 \pm 1.0^{\mathrm{e}}$ \\
\hline \multirow[t]{2}{*}{ Delta serum PTH (pmol/L) } & Vitamin D & $-1.4 \pm 1.8^{c}$ & $-0.6 \pm 1.4^{c}$ & $-0.7 \pm 1.5^{c}$ & $-0.3 \pm 1.5^{a}$ & $-0.8 \pm 1.6^{\mathrm{ad}}$ \\
\hline & Placebo & $0.0 \pm 1.5$ & $0.3 \pm 1.7$ & $0.3 \pm 1.6$ & $0.2 \pm 0.9$ & $0.5 \pm 1.0$ \\
\hline \multirow[t]{2}{*}{ Baseline serum calcium (mmol/L) } & Vitamin D & $2.28 \pm 0.07$ & $2.29 \pm 0.08$ & $2.30 \pm 0.10$ & $2.31 \pm 0.08$ & $2.34 \pm 0.07^{d}$ \\
\hline & Placebo & $2.27 \pm 0.07$ & $2.28 \pm 0.08$ & $2.31 \pm 0.09$ & $2.31 \pm 0.08$ & $2.30 \pm 0.06^{e}$ \\
\hline \multirow[t]{2}{*}{ Delta serum calcium (mmol/L) } & Vitamin D & $0.01 \pm 0.07$ & $0.00 \pm 0.09^{b}$ & $-0.02 \pm 0.09$ & $-0.02 \pm 0.10$ & $-0.07 \pm 0.05^{a e}$ \\
\hline & Placebo & $0.00 \pm 0.07$ & $-0.02 \pm 0.09$ & $-0.03 \pm 0.08$ & $-0.04 \pm 0.09$ & $-0.02 \pm 0.07$ \\
\hline
\end{tabular}

Delta values are end of study values minus baseline (for the Prevention of T2DM study 1-year values minus baseline).

${ }^{a} P<0.05 ;{ }^{b} P<0.01 ;{ }^{c} P<0.001$ (vs placebo group, Student's $t$-test); ${ }^{\mathrm{d}} P<0.01 ; \mathrm{e} P<0.001$ (linear trend); ${ }^{\mathrm{P}}$ Subjects from the Obesity, Depression, Glucose clamp, CVD risk factors, and Prevention of T2DM pooled together. Only subjects who completed the intervention with valid serum 25(OH)D and PTH measurements are included. 
Table 4 Serum 25(OH)D, PTH, and delta PTH in 116 subjects given vitamin D and 111 placebo and who completed the 5-year intervention in the prevention of T2DM study.

\begin{tabular}{|c|c|c|c|c|}
\hline & \multicolumn{2}{|c|}{ Serum $25(\mathrm{OH}) \mathbf{D}(\mathrm{nmol} / \mathrm{L})$} & \multicolumn{2}{|c|}{ Serum PTH (pmol/L) } \\
\hline & Vitamin D & Placebo & Vitamin D & Placebo \\
\hline Baseline & $63 \pm 23$ & $63 \pm 21$ & $5.7 \pm 2.1$ & $5.5 \pm 2.4$ \\
\hline 1 year & $110 \pm 30^{c}$ & $65 \pm 22$ & $5.2 \pm 1.6$ & $5.7 \pm 1.9$ \\
\hline 2 years & $114 \pm 24^{c}$ & $64 \pm 19$ & $5.5 \pm 2.0$ & $5.7 \pm 1.7$ \\
\hline 3 years & $118 \pm 26^{c}$ & $66 \pm 20$ & $5.4 \pm 1.9$ & $6.0 \pm 2.3$ \\
\hline 4 years & $120 \pm 26^{c}$ & $65 \pm 19$ & $5.3 \pm 2.1$ & $5.7 \pm 1.9$ \\
\hline 5 years & $122 \pm 25^{c}$ & $67 \pm 19$ & $5.2 \pm 1.7$ & $5.7 \pm 2.3$ \\
\hline
\end{tabular}

\begin{tabular}{|c|c|}
\hline \multicolumn{2}{|c|}{ Delta serum PTH $(\mathrm{pmol} / \mathrm{L})^{a}$} \\
\hline Vitamin D & Placebo \\
\hline$-0.6 \pm 1.5^{b}$ & $0.2 \pm 1.7$ \\
\hline$-0.2 \pm 1.5$ & $0.2 \pm 1.8$ \\
\hline$-0.3 \pm 1.6^{c}$ & $0.5 \pm 1.5$ \\
\hline$-0.4 \pm 1.6^{b}$ & $0.3 \pm 2.0$ \\
\hline$-0.5 \pm 1.4^{c}$ & $0.2 \pm 1.4$ \\
\hline
\end{tabular}

${ }^{a}$ Annual serum PTH value minus baseline PTH; ${ }^{b} p<0.01 ;{ }^{c} p<0.001$ (vs placebo group, Student's $t$-test)

in the group given $5600 \mathrm{IU}$ per week was $\sim 20 \mathrm{nmol} / \mathrm{L}$. At all 3-month intervals, the decrease in serum PTH was significantly higher in those given 45,600 IU per week and, as in the Obesity study, the lowest PTH levels were seen already after 3 months (Table 6).

\section{Discussion}

In the cross-sectional part of the present study, we have confirmed the well-known inverse relationship between serum 25(OH)D and PTH, but could not find a 25(OH)D level where the serum PTH stabilized or reached a plateau. In the intervention studies, the decrease in serum PTH by vitamin D supplementation was dose dependent and occurred within 3 months with no further suppression thereafter. And most importantly, the serum PTH level was significantly supressed by vitamin $\mathrm{D}$ supplementation even in subjects with serum $25(\mathrm{OH}) \mathrm{D}$ levels $>100 \mathrm{nmol} / \mathrm{L}$.

There are numerous cross-sectional reports on thresholds for serum 25(OH)D suppression of serum PTH $(10,11,12,23,24,25)$. This has been estimated by advanced statistical methods $(10,12)$ as well as with simple visual curve inspection (12). The cohorts included have differed widely as have the results. As examples can be mentioned, in the large study by Saliba et al., including 19,172 subjects from an Israeli clinical laboratory database, a serum 25(OH)D threshold of 79 $\mathrm{nmol} / \mathrm{L}$ was found. However, after excluding subjects with hypercalcemia and reduced kidney function, the threshold was reduced to $46 \mathrm{nmol} / \mathrm{L}$ (11). In a study by Sohl et al., including 1164 elderly subjects, the threshold for women was $68 \mathrm{nmol} / \mathrm{L}$, whereas in men the threshold was $45 \mathrm{nmol} / \mathrm{L}$. In the same study, the $25(\mathrm{OH}) \mathrm{D}$ threshold was also affected by BMI, being $47 \mathrm{nmol} / \mathrm{L}$ in those with BMI $<25 \mathrm{~kg} / \mathrm{m}^{2}$ and $62 \mathrm{nmol} / \mathrm{L}$ in those with higher BMI (12). Among 1258 Caucasians, Wright et al. found a threshold of approximately $75 \mathrm{nmol} / \mathrm{L}$, whereas in 423 African Americans the threshold was approximately 50 $\mathrm{nmol} / \mathrm{L}$ (24). In a study by Durazo-Arvizu et al., including 387 subjects from an osteoporosis treatment/prevention study and using a three-phase model, two thresholds (or significant change in the serum PTH-25(OH)D curve) of 30 and $70 \mathrm{nmol} / \mathrm{L}$ could be identified (10). And finally, in 500 adults of African ancestry, there was an almost linear

Table 5 Serum 25(OH)D, PTH, and delta PTH in the 332 subjects who completed the 1-year intervention in the obesity study.

\begin{tabular}{l}
\hline \\
\hline Serum 25(OH)D (nmol/L) \\
Vitamin D 40,000 IU per week $(n=114)$ \\
Vitamin D 20,000 IU per week $(n=106)$ \\
Placebo $(n=112)$ \\
Serum PTH (pmol/L) \\
Vitamin D 40,000 IU per week $(n=114)$ \\
Vitamin D 20,000 IU per week $(n=106)$ \\
Placebo $(n=112)$ \\
Delta serum PTH (pmol/L) \\
Vitamin D 40,000 IU per week $(n=114)$ \\
Vitamin D 20,000 IU per week $(n=106)$ \\
Placebo $(n=112)$
\end{tabular}

\begin{tabular}{r}
\hline Baseline \\
\hline $56 \pm 16$ \\
$53 \pm 19$ \\
$53 \pm 16$ \\
$5.1 \pm 1.6$ \\
$5.5 \pm 1.8$ \\
$5.6 \pm 1.6$ \\
\end{tabular}

\begin{tabular}{c}
\hline 3 months \\
\hline $108 \pm 22^{\mathrm{cd}}$ \\
$88 \pm 20^{\mathrm{c}}$ \\
$56 \pm 17$ \\
$3.4 \pm 1.2$ \\
$4.0 \pm 1.7$ \\
$4.4 \pm 1.8$ \\
$-1.8 \pm 1.5^{\mathrm{a}}$ \\
$-1.5 \pm 1.4$ \\
$-1.2 \pm 1.6$ \\
\hline
\end{tabular}

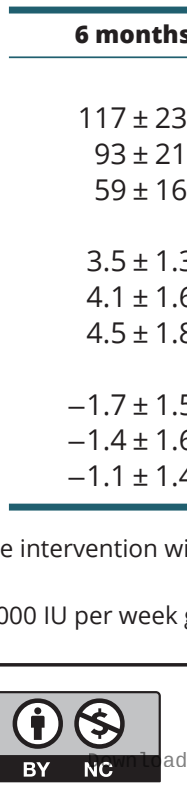

\begin{tabular}{cccc}
\hline 9 months & & 12 months \\
\cline { 1 - 1 } $121 \pm 28^{\text {cd }}$ & & $116 \pm 27^{c d}$ \\
$95 \pm 21^{c}$ & & $91 \pm 22^{c}$ \\
$56 \pm 15$ & & $51 \pm 14$ \\
& & \\
$3.6 \pm 1.4$ & & $4.2 \pm 1.5$ \\
$4.2 \pm 1.6$ & & $4.7 \pm 1.7$ \\
$4.6 \pm 1.6$ & & $5.4 \pm 1.9$ \\
& & \\
$-1.6 \pm 1.5^{a}$ & & $-0.9 \pm 1.5^{b}$ \\
$-1.3 \pm 1.4$ & & $-0.8 \pm 1.4^{b}$ \\
$-1.0 \pm 1.7$ & & $-0.3 \pm 1.6$ \\
\hline
\end{tabular}

Delta values are the specific month value minus baseline. Only subjects who completed the intervention with valid serum 25(OH)D and PTH measurements are included.

${ }^{\mathrm{a}} P<0.05 ;{ }^{\mathrm{b}} P<0.01 ;{ }^{\mathrm{c}} P<0.001$ (Vs placebo, Student's $t$-test); ${ }^{\mathrm{d}} P<0.001$ (vs the vitamin $\mathrm{D} 20,000$ IU per week group, Student's $t$-test). 
Table 6 Serum 25(OH)D, PTH, and delta PTH in the 273 postmenopausal women who completed the 1-year intervention in the Osteoporosis study.

\begin{tabular}{|c|c|c|c|c|c|}
\hline & Baseline & 3 months & 6 months & 9 months & 12 months \\
\hline \multicolumn{6}{|l|}{ Serum 25(OH)D (nmol/L) } \\
\hline Vitamin D 45,600 IU per week $(n=135)$ & $71 \pm 23$ & $168 \pm 27^{b}$ & $177 \pm 32^{b}$ & $187 \pm 32^{b}$ & $186 \pm 34^{b}$ \\
\hline Vitamin D 5600 IU per week $(n=140)$ & $71 \pm 22$ & $91 \pm 19$ & $93 \pm 24$ & $90 \pm 18$ & $89 \pm 17$ \\
\hline \multicolumn{6}{|l|}{ Serum PTH (pmol/L) } \\
\hline Vitamin D 45,600 IU per week $(n=135)$ & $5.0 \pm 1.6$ & $3.5 \pm 1.3$ & $3.7 \pm 1.2$ & $3.7 \pm 1.2$ & $3.9 \pm 1.1$ \\
\hline Vitamin D 5600 IU per week $(n=140)$ & $5.0 \pm 1.6$ & $3.9 \pm 1.3$ & $4.2 \pm 1.5$ & $4.2 \pm 1.5$ & $4.5 \pm 1.5$ \\
\hline \multicolumn{6}{|l|}{ Delta serum PTH (pmol/L) } \\
\hline Vitamin D 45,600 IU per week $(n=135)$ & & $-1.5 \pm 1.2^{\mathrm{a}}$ & $-1.4 \pm 1.4^{\mathrm{b}}$ & $-1.3 \pm 1.5^{b}$ & $-1.2 \pm 1.4^{b}$ \\
\hline Vitamin D 5600 IU per week $(n=140)$ & & $-1.1 \pm 1.4$ & $-0.8 \pm 1.5$ & $-0.8 \pm 1.4$ & $-0.6 \pm 1.5$ \\
\hline
\end{tabular}

Delta values are the specific month value minus baseline. Only subjects who completed the intervention with valid serum 25(OH)D and PTH measurements are included. All subjects were given $1000 \mathrm{mg}$ calcium daily.

${ }^{a} P<0.05 ;{ }^{b} P<0.01$ (vs vitamin D 5600 IU per week, Student's $t$-test).

relation between serum PTH and 25(OH)D in the serum 25(OH)D 25-150 nmol/L range (23).

Our observational study adds to this multitude of thresholds or lack of such. In the males, the decrease in serum PTH in those with serum $25(\mathrm{OH}) \mathrm{D}>50-75$ $\mathrm{nmol} / \mathrm{L}$ was marginal, whereas in the females no plateau was reached, at least not below $100 \mathrm{nmol} / \mathrm{L}$. Even if the ideal observational study on the serum PTH-25(OH)D relation was performed in a population-based cohort where adjustments could be made for relevant factors like calcium and magnesium intake and where the number of subjects were large enough to do subgroup analyses in males and females, in young and old, in low-, normal-, and overweight subjects, one would not be able to reliably identify a threshold (or lack of such) where no additional, meaningful PTH suppression by vitamin D would occur. This is simply because one cannot imply causality from observational data, and the $25(\mathrm{OH}) \mathrm{D}$ threshold, similar to health effects of vitamin D, has to be tested in RCTs $(4,26)$.

The effect of vitamin D on serum PTH in RCTs was systematically reviewed by Björkman et al., where 41 clinical trials were included, and the results suggested that serum PTH would decrease quite linearly during vitamin D supplementation at any given serum 25(OH)D level (14). However, in the majority of the studies, the mean baseline serum 25(OH)D level was $<50 \mathrm{nmol} / \mathrm{L}$ and no study had mean baseline serum $25(\mathrm{OH}) \mathrm{D}>85 \mathrm{nmol} / \mathrm{L}$. Individual person data (IPD) were not used in the analyses, and accordingly, the PTH-25(OH)D relation in subjects with serum $25(\mathrm{OH}) \mathrm{D}>85 \mathrm{nmol} / \mathrm{L}$ not investigated.

In our intervention studies, we found that the serum PTH suppression by vitamin D appeared to reach its full effect after 3 months as demonstrated in the Obesity and Osteoporosis studies and that even 5 years with continuously high serum 25(OH)D levels had no additional effect in the Prevention of T2DM study. Furthermore, we confirmed the importance of the vitamin D dose given (27), as the suppression of serum PTH in the Osteoporosis study was considerably higher with vitamin D 45,600 IU per week vs the 5600 IU per week. On the other hand, there was no significant difference in PTH suppression between 40,000 IU per week vs 20,000 IU per week in the Obesity study. We, therefore, found it relevant to pool the baseline and end of study (or 1 year) IPD from the Obesity, Depression, Glucose clamp, CVD risk factors, and the Prevention of T2DM studies, even though different vitamin $\mathrm{D}$ doses and intervention times were used. With this approach the cohort became sufficiently large to allow meaningful analyses of PTH suppression in a broad range of baseline serum 25(OH)D levels.

As expected, the suppression was most pronounced in those with low baseline serum $25(\mathrm{OH}) \mathrm{D}$, who also had the highest baseline PTH and, also as expected (28), the highest increase in serum $25(\mathrm{OH}) \mathrm{D}$ after supplementation. However, there was a substantial and statistically significant decrease in serum PTH even in those with baseline serum $25(\mathrm{OH}) \mathrm{D}>100 \mathrm{nmol} / \mathrm{L}$. This reduction in serum PTH was statistically significant also after adjusting for the concomitant changes in serum calcium, indicating a direct effect by vitamin D on the PTH synthesis/ secretion. Accordingly, it is very difficult to justify using cross-sectional data to identify a $25(\mathrm{OH}) \mathrm{D}$ threshold at a serum 25(OH)D level of $\sim 50 \mathrm{nmol} / \mathrm{L}$. In addition, serum PTH suppression is for vitamin D supplementation only a surrogate marker for health effects and should not be used to define vitamin D sufficiency.

Even though there are strong indications for extraskeletal effects of vitamin D, like the wide tissue distributing of the vitamin D receptor (VDR) and the enzymes necessary for activation of vitamin D (1), together with all 


\section{(n)}

the favourable observational studies, firm evidence from RCTs is lacking $(3,29)$. Estimates of vitamin D thresholds based on extra-skeletal effects of vitamin D are therefore at present not relevant. For fractures, on the other hand, there appears to be fairly good evidence for a protective effect of combined use of calcium and vitamin $\mathrm{D}$, but this has so far not been definitely related to a serum 25(OH)D level (29).

Serum PTH is the parameter most consistently associated with serum 25(OH)D both in cross-sectional and interventional studies. In spite of this, a wide range of $25(\mathrm{OH}) \mathrm{D}$ thresholds have been reported, which probably also will be the case for skeletal effects of vitamin D. It is also likely that such a serum $25(\mathrm{OH}) \mathrm{D}$ threshold will be affected by calcium intake, similar to what is seen for the risk of rickets in children where a high calcium intake is protective (29). A high calcium intake increases the half-life of 25(OH)D and may thus be good for the vitamin D economy (30). This may influence the $25(\mathrm{OH}) \mathrm{D}-\mathrm{PTH}$ relation, as demonstrated by Patel et al. who found lower serum PTH values for given $25(\mathrm{OH}) \mathrm{D}$ concentrations in subjects with high calcium intake (31). A low dietary magnesium intake may also alter the 25(OH)D-PTH relationship, at least in overweight or obese subjects (32). Differences in calcium and magnesium intakes may therefore partly explain the wide range in $25(\mathrm{OH}) \mathrm{D}$ thresholds reported. Additionally, other factors like BMI, age, ethnicity, and gender may influence the threshold, which may even differ between the endpoints used for threshold identification $(12,24)$. Finding a clinically relevant and trustworthy threshold for vitamin D sufficiency may therefore prove difficult.

Our study has several weaknesses. Although we had large cohorts both in the observational and interventional parts of the study, relatively few subjects had very high baseline serum 25(OH)D levels. Therefore, we cannot draw conclusions about the serum PTH-25(OH)D relation in subjects with serum $25(\mathrm{OH}) \mathrm{D}>\sim 125 \mathrm{nmol} / \mathrm{L}$. Although we feel we have justified pooling the five intervention studies together, they were still different studies with different inclusion criteria and interventions. Furthermore, different laboratories and assays were used for the $25(\mathrm{OH}) \mathrm{D}$ and PTH measurements, without any formal examination of consistency between the analytic methods. This could be of particular importance for PTH where there is no standardization program, and we cannot rule out that this may have affected the results. On the other hand, our study also has several strengths. In the observational part, we only included subjects with normal serum calcium and creatinine levels, and in the interventional part, we examined the PTH-25(OH)D relation over a broad range of serum 25(OH)D levels.
In conclusion, we have found that serum PTH is suppressed by vitamin $\mathrm{D}$ supplementation even if the baseline serum $25(\mathrm{OH}) \mathrm{D}$ is $>100 \mathrm{nmol} / \mathrm{L}$. This argues against using serum PTH suppression to define vitamin D sufficiency.

\section{Declaration of interest}

The authors declare that there is no conflict of interest that could be perceived as prejudicing the impartiality of the research reported.

\section{Funding}

The Tromsø study was supported by grants from the North Norway Regional Health Authorities (grant number SFP1277-16) and UiT The Arctic University of Norway; the Obesity and Depression studies supported by grants from The Northern Norway Regional Health Authority; the Glucose clamp and Osteoporosis studies supported by the Norwegian Council of Cardiovascular Disease; the CVD risk factor study supported by grants from the North Norway Regional Health Authorities (grant number SFP1277-16) and UiT The Arctic University of Norway; and the Prevention of T2DM supported by grants from the Novo Nordisk Foundation (Grant R195-A16126), the North Norway Regional Health Authorities (Grant 6856/ SFP1029-12), UiT The Arctic University of Norway, the Norwegian Diabetes Association, and the Research Council of Norway (Grant 184766).

\section{Acknowledgements}

The superb assistance from the staff at the Clinical Research Unit at the University Hospital of North Norway is gratefully acknowledged.

\section{References}

1 DeLuca HF. Overview of general physiologic features and functions of vitamin D. American Journal of Clinical Nutrition 200480 1689S-1696S. (https://doi.org/10.1093/ajcn/80.6.1689S)

2 Holick MF. Vitamin D deficiency. New England Journal Medicine 2007 357 266-281. (https://doi.org/10.1056/NEJMra070553)

3 Theodoratou E, Tzoulaki I, Zgaga L \& Ioannidis JP. Vitamin D and multiple health outcomes: umbrella review of systematic reviews and meta-analyses of observational studies and randomised trials. BMJ 2014348 g2035. (https://doi.org/10.1136/bmj.g2035)

4 Bouillon R, Van Schoor NM, Gielen E, Boonen S, Mathieu C, Vanderschueren D \& Lips P. Optimal vitamin D status: a critical analysis on the basis of evidence-based medicine. Journal of Clinical Endocrinology and Metabolism 201398 E1283-E1304. (https://doi. org/10.1210/jc.2013-1195)

5 Martineau AR, Jolliffe DA, Hooper RL, Greenberg L, Aloia JF, Bergman P, Dubnov-Raz G, Esposito S, Ganmaa D, Grinde AA, et al. Vitamin D supplementation to prevent acute respiratory tract infections: systematic review and meta-analysis of individual participant data. BMJ 2017356 i6583. (https://doi.org/10.1136/bmj. i6583)

6 Institute of Medicine. Dietary Reference Intakes for Calcium and Vitamin D. Washington, DC, USA: The National Academies Press, 2011.

7 Holick MF, Binkley NC, Bischoff-Ferrari HA, Gordon CM, Hanley DA, Heaney RP, Murad MH, Weaver CM \& Endocrine Society. Evaluation, treatment, and prevention of vitamin D deficiency: an Endocrine Society clinical practice guideline. Journal of Clinical Endocrinology and Metabolism 201196 1911-1930. (https://doi.org/10.1210/jc.20110385)

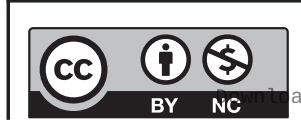

This work is licensed under a Creative Commons Attribution-NonCommercial 4.0 International License. ded from Bioscientifica,com at 04/26/2023 06:22:13AM 


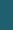

8 Priemel M, von Domarus C, Klatte TO, Kessler S, Schlie J, Meier S, Proksch N, Pastor F, Netter C, Streichert T, et al. Bone mineralization defects and vitamin D deficiency: histomorphometric analysis of iliac crest bone biopsies and circulating 25-hydroxyvitamin D in 675 patients. Journal of Bone and Mineral Research 201025 305-312. (https://doi.org/10.1359/jbmr.090728)

9 Kumar R \& Thompson JR. The regulation of parathyroid hormone secretion and synthesis. Journal of American Society of Nephrology 2011 22 216-224. (https://doi.org/10.1681/ASN.2010020186)

10 Durazo-Arvizu RA, Dawson-Hughes B, Sempos CT, Yetley EA, Looker AC, Cao G, Harris SS, Burt VL, Carriquiry AL \& Picciano MF. Three-phase model harmonizes estimates of the maximal suppression of parathyroid hormone by 25 -hydroxyvitamin $\mathrm{D}$ in persons 65 years of age and older. Journal of Nutrition 2010140 595-599. (https://doi. org/10.3945/jn.109.116681)

11 Saliba W, Barnett O, Rennert HS, Lavi I \& Rennert G. The relationship between serum $25(\mathrm{OH}) \mathrm{D}$ and parathyroid hormone levels. American Journal of Medicine 2011124 1165-1170. (https://doi. org/10.1016/j.amjmed.2011.07.009)

12 Sohl E, de Jongh RT, Heymans MW, van Schoor NM \& Lips P. Thresholds for serum 25(OH)D concentrations with respect to different outcomes. Journal of Clinical Endocrinology and Metabolism 2015100 2480-2488. (https://doi.org/10.1210/jc.2015-1353)

13 Asghari G, Yuzbashian E, Wagner CL, Mahdavi M, Shamsi R, Hosseinpanah F \& Mirmiran P. The relation between circulating levels of vitamin D and parathyroid hormone in children and adolescents with overweight or obesity: quest for a threshold. PLoS One 201914 e0225717. (https://doi.org/10.1371/journal. pone.0225717)

14 Björkman M, Sorva A \& Tilvis R. Responses of parathyroid hormone to vitamin D supplementation: a systematic review of clinical trials. Archives of Gerontology and Geriatrics 200948 160-166. (https://doi. org/10.1016/j.archger.2007.12.005)

15 Jacobsen BK, Eggen AE, Mathiesen EB, Wilsgaard T \& Njølstad I. Cohort profile: the Tromso Study. International Journal of Epidemiology 201241 961-967. (https://doi.org/10.1093/ije/dyr049)

16 Jorde R \& Grimnes G. Lost relation between blood pressure and serum 25-hydroxyvitamin D. Blood Pressure 201928 64-73. (https:// doi.org/10.1080/08037051.2018.1547628)

17 Sneve M, Figenschau Y \& Jorde R. Supplementation with cholecalciferol does not result in weight reduction in overweight and obese subjects. European Journal of Endocrinology 2008159 675-684. (https://doi.org/10.1530/EJE-08-0339)

18 Kjærgaard M, Waterloo K, Wang CE, Almås B, Figenschau Y, Hutchinson MS, Svartberg J \& Jorde R. Effect of vitamin D supplement on depression scores in people with low levels of serum 25-hydroxyvitamin D: nested case-control study and randomised clinical trial. British Journal of Psychiatry 2012201 360-368. (https:// doi.org/10.1192/bjp.bp.111.104349)

19 Grimnes G, Figenschau Y, Almås B \& Jorde R. Vitamin D, insulin secretion, sensitivity, and lipids: results from a case-control study and a randomized controlled trial using hyperglycemic clamp technique. Diabetes 201160 2748-2757. (https://doi.org/10.2337/db11-0650)

20 Grimnes G, Joakimsen R, Figenschau Y, Torjesen PA, Almås B \& Jorde R. The effect of high-dose vitamin D on bone mineral density and bone turnover markers in postmenopausal women with low bone mass - a randomized controlled 1-year trial. Osteoporosis
International 201223 201-211. (https://doi.org/10.1007/s00198-0111752-5)

21 Kubiak J, Thorsby PM, Kamycheva E \& Jorde R. Vitamin D supplementation does not improve CVD risk factors in vitamin D-insufficient subjects. Endocrine Connections 20187 840-849. (https://doi.org/10.1530/EC-18-0144)

22 Jorde R, Sollid ST, Svartberg J, Schirmer H, Joakimsen RM, Niølstad I, Fuskevåg OM, Figenschau Y \& Hutchinson MY. Vitamin D 20,000 IU per week for five years does not prevent progression from prediabetes to diabetes. Journal of Clinical Endocrinology and Metabolism 2016101 1647-1655. (https://doi.org/10.1210/jc.2015-4013)

23 Kramer H, Camacho P, Aloia J, Luke A, Bovet P, Rhule JP, Forrester T, Lambert V, Harders R, Dugas L, et al. Association between 25-hydroxyvitamin D and intact parathyroid hormone levels across latitude among adults of African ancestry. Endocrine Practice 201622 911-919. (https://doi.org/10.4158/EP151079.OR)

24 Wright NC, Chen L, Niu J, Neogi T, Javiad K, Nevitt MA, Lewis CE \& Curtis JR. Defining physiologically 'normal' vitamin D in African Americans. Osteoporosis International 201223 2283-2291. (https:// doi.org/10.1007/s00198-011-1877-6)

25 Holick MF, Siris ES, Binkley N, Beard MK, Khan A, Katzer JT, Petruschke RA, Chen E \& de Papp AE. Prevalence of Vitamin D inadequacy among postmenopausal North American women receiving osteoporosis therapy. Journal of Clinical Endocrinology and Metabolism 200590 3215-3224. (https://doi.org/10.1210/jc.2004-2364)

26 Jorde R \& Grimnes G. Vitamin D and health: the need for more randomized controlled trials. Journal of Steroid Biochemistry and Molecular Biology 2015148 269-274. (https://doi.org/10.1016/j. jsbmb.2015.01.021)

27 Smith LM \& Gallagher JC. Effect of vitamin D supplementation on total and free 25 hydroxyvitamin $\mathrm{D}$ and parathyroid hormone. An analysis of two randomized controlled trials. Journal of Internal Medicine 2019286 651-659. (https://doi.org/10.1111/joim.12950)

28 Didriksen A, Grimnes G, Hutchinson MS, Kjærgaard M, Svartberg J, Joakimsen RM \& Jorde R. The serum 25-hydroxyvitamin D response to vitamin D supplementation is related to genetic factors, BMI, and baseline levels. European Journal of Endocrinology 2013169 559-567. (https://doi.org/10.1530/EJE-13-0233)

29 Bouillon R, Marcocci C, Carmeliet G, Bikle D, White JH, DawsonHughes B, Lips P, Munns CF, Lazaretti-Castro M Giustina A, et al. Skeletal and extraskeletal actions of vitamin D: current evidence and outstanding questions. Endocrine Reviews 201940 1109-1151. (https://doi.org/10.1210/er.2018-00126)

30 Lips P. Interaction between vitamin D and calcium. Scandinavian Journal of Clinical and Laboratory Investigation 201272 (Supplement 243) 60-64. (https://doi.org/10.3109/00365513.2012.681960)

31 Patel P, Mughal MZ, Patel P, Yagnik B, Kajale N, Mandlik R, Khadilkar V, Chiplonkar SA, Phanse S, Patwardhan V, et al. Dietary calcium intake influences the relationship between serum 25-hydroxyvitamin D3 (25OHD) concentration and parathyroid hormone (PTH) concentration. Archives of Disease in Childhood 2016 101 316-319. (https://doi.org/10.1136/archdischild-2015-308985)

32 Cheung MM, DeLuccia R, Ramadoss RK, Aljahdali A, Volpe SL, Shewokis PA \& Sukumar D. Low dietary magnesium intake alters vitamin D-parathyroid hormone relationship in adults who are overweight or obese. Nutrition Research 201969 82-93. (https://doi. org/10.1016/j.nutres.2019.08.003)

Received in final form 8 April 2020

Accepted 21 April 2020

Accepted Manuscript published online 21 April 2020 https://ec.bioscientifica.com https://doi.org/10.1530/EC-20-0067 (c) 2020 The authors Published by Bioscientifica Ltd

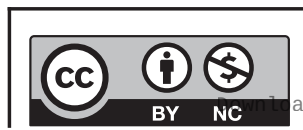

This work is licensed under a Creative Commons Attribution-NonCommercial 4.0 International License. ded from Bioscientifica.com at 04/26/2023 06:22:13AM 